\title{
OS JOGOS E O PROCESSO DE APRENDIZAGEM DA LÍNGUA INGLESA
}

\author{
THE GAMES AND ENGLISH LANGUAGE LEARNING PROCESS
}

\section{LOS JUEGOS Y EL PROCESO DE APRENDIZAJE DE LA LENGUA INGLESA}

\author{
Giovanni Oliveira Bonati \\ Licenciado em Letras - Faculdades Integradas de Jaú \\ Docente de Curso de Idiomas \\ E-mail: giovannibonati@hotmail.com
}

\author{
Wanderlei Sebastião Gabini \\ Pós-Doutorado em Educação - UNESP - Botucatu \\ Doutorado em Educação para a Ciência - UNESP - Bauru \\ Mestrado em Educação para a Ciência - UNESP - Bauru \\ Licenciado em Química - Universidade Federal de São Carlos - São Carlos \\ Licenciado em Pedagogia - Faculdade de Filosofia, Ciências e Letras de Botucatu - Botucatu \\ Docente das Faculdades Integradas de Jaú \\ E-mail: wgabini@uol.com.br
}

\section{RESUMO}

Os métodos tradicionais de ensino de língua inglesa como segunda língua enfrentam um problema de falta de contextualização em relação ao estilo de vida do estudante do século XXI, o nativo digital. O mundo globalizado e com forte presença das tecnologias da informação em quase todas as situações na sociedade, tecnologias que tem íntima relação com a língua inglesa, exige uma inclusão dessas novas ferramentas no processo de ensino. O objetivo geral da pesquisa encontra-se na análise da inserção de alguns gêneros de videogames como tecnologias da informação no ensino de língua inglesa, baseando-se em uma análise bibliográfica que foi feita a partir de contribuições de autores acerca do tema. Alicerçado a isso, tem-se a constatação de que alguns videogames contribuem para o ensino de língua inglesa como segunda língua por proporcionarem ambientes de aprendizado que desenvolvem a autonomia e conduzem um ambiente divertido e motivador. Além disso, os conteúdos da língua estudada aparecem como inputs, que são relacionados e assimilados durante desafios.

Palavras-chave: Ensino de língua inglesa. TICs na educação. Videogames.

\section{ABSTRACT}

The traditional methods of English teaching as second language face a problem of lack of context in relation to the 21 st century student lifestyle, the digital native. The globalized world, that contains a strong presence of information technologies in almost all situations in society, 
technologies that are closely related to the English language, requires the inclusion of these new tools in the teaching process. The most important goal of the research is found in the analysis of the insertion of some genres of video games as information technologies in English teaching, based on a bibliographic analysis that was made from contributions of authors on the subject. Based on this, it has been found that some video games contribute to the teaching of English as a second language by providing learning environments that develop autonomy and lead to a fun and motivating environment. In addition to it, contents of the studied language appear as inputs, which are related and assimilated during challenges.

Keywords : English language teaching. ICTs in education. Video games.

\section{RESUMEN}

Los métodos tradicionales de enseñanza del inglés como segunda lengua enfrentan un problema de falta de contextualización en relación con el estilo de vida del estudiante del siglo XXI, el nativo digital. El mundo globalizado y con una fuerte presencia de las tecnologías de la información en casi todas las situaciones de la sociedad, tecnologías que tienen íntima relación con la lengua inglesa, requiere la inclusión de estas nuevas herramientas en el proceso de enseñanza. El objetivo general de la investigación se encuentra en el análisis de la inserción de algunos géneros de videojuegos como tecnologías de la información en la enseñanza de lengua inglesa, basándose un análisis bibliográfico que se hizo a partir de aportes de autores sobre el tema. En base a esto, se ha encontrado que algunos videojuegos contribuyen a la enseñanza del inglés como segunda lengua proporcionando entornos de aprendizaje que desarrollan la autonomía y conducen a un ambiente divertido y motivador. Además, aparecen como inputs los contenidos del idioma estudiado, que se relacionan y asimilan durante los desafíos.

Palabras clave: Enseñanza de lengua inglesa. TICs em educación. Videojuegos

\section{INTRODUÇÃO}

O aluno que estuda a língua inglesa como língua estrangeira se sente desmotivado e desinteressado em diversas realidades escolares. Por isso, surgiram várias discussões acerca da necessidade de mudança no que se diz respeito ao ensino de língua inglesa como língua estrangeira. A desmotivação aparece em um momento em que os alunos são diferentes. $\mathrm{O}$ mundo globalizado e cheio de tecnologias mudou as estruturas da sociedade e até o modo de assimilar conhecimentos.

Os métodos mais tradicionais de ensino não incluem a presença constante das tecnologias na sociedade atual, fazendo com que os aprendizes não se sintam familiarizados com aqueles conteúdos, já que parecem não se encaixarem na realidade do mesmo. A introdução das tecnologias da informação e comunicação (TIC) no processo de aprendizado da língua inglesa se tornou alvo de estudos, principalmente no século XXI, fazendo com que essas discussões se tornassem cada vez mais presentes. 
O ponto mais importante desta pesquisa encontra-se na análise dos benefícios da utilização de uma tecnologia específica no ensino de língua inglesa, o jogo digital. Os jogos digitais, ou videogames, são tecnologias extremamente presentes no estilo de vida do jovem inserido no mundo globalizado, além de possuírem bastante relação com países falantes da língua inglesa, já que grande parte desses produtos são produzidos nesses países. Além disso, este trabalho aponta relações de alguns gêneros de videogame com estruturas linguísticas da língua inglesa.

Por consequência, o objetivo geral se concentra em analisar a inserção de alguns gêneros de videogames como tecnologias da informação no ensino de língua inglesa, apontando seus benefícios e quais são os seus papéis durante seus usos. A interpretação das informações selecionadas a partir da pesquisa bibliográfica permitiu que fossem estabelecidos os grandes pontos de análise nesse estudo, um olhar que considerou as premissas sobre as frequentes transformações da realidade.

\section{EDUCAÇÃO, SOCIEDADE E TECNOLOGIAS}

As definições das funções da educação variam de acordo com o contexto histórico e com a situação em que a sociedade está inserida. Os sistemas de educação, historicamente, dependeram de fatores como organização política, religião, grau de desenvolvimento das ciências, e entre outros para se desenvolverem. Durkheim (1975). De acordo com essa afirmação, é possível dizer que a forma de educar varia de acordo com as características de uma sociedade. Necessidades de mudanças nos processos de educação sempre acontecem nas sociedades, a mais recente tem relação direta com o ápice de desenvolvimento das tecnologias de informação.

O mundo globalizado do século XXI tem como principal característica a presença das tecnologias como mediadoras das relações sociais, aspecto que impactou e a educação, causando uma necessidade de mudança.

A disseminação e uso de tecnologias digitais, marcadamente dos computadores e da internet, favoreceu o desenvolvimento de uma cultura de uso das mídias e, por conseguinte, de uma configuração social pautada num modelo digital de pensar, criar, produzir, comunicar, aprender-viver [...] (ALMEIDA; SILVA, 2011, p. 4) 
Segundo Blanco e Silva (1993), o termo tecnologia pode ser definido como um conjunto de utensílios e máquinas que auxiliam na operação de ofícios. Por isso, podem ser denominados dessa forma todos os recursos que auxiliam na execução de uma tarefa. Esses recursos mudam e se desenvolvem no decorrer da história da humanidade, como por exemplo, o desenvolvimento das tecnologias de informação no século XXI, ocasionando uma nova estruturação da sociedade. Cruz e Bizelli (2014, p. 259) afirmam que "compreender e dominar os códigos das novas tecnologias se torna relevante para produzir e absorver os conteúdos para gerar inovações"'.

A forte influência das tecnologias nas relações sociais definiu o que conhecemos hoje como "sociedade da informação". Na sociedade da informação, as atividades humanas podem ser executadas pelo uso, parcial ou integral das tecnologias da informação. "Numa Sociedade de Informação, as pessoas aproveitam as vantagens das tecnologias em todos os aspectos das suas vidas: no trabalho, em casa e no lazer" (GOUVEIA, 2004). O conceito de lazer na sociedade de informação está intimamente atrelado à atividades conhecidas como "virtuais", como o videogame, por exemplo.

Essas diversas modificações sociais originadas pelo desenvolvimento das tecnologias de informação resultam na necessidade de explorar novos métodos de ensino, já que metodologias tradicionais que não levam em conta a influência tecnológica não se encaixam na realidade dos alunos deste tempo.

Valente (1999) aborda uma importante tendência de mudança no que se diz respeito às formas de educar na sociedade de informação. Para ele, noutro tempo, a transmissão do conhecimento acontecia exclusivamente a partir do professor, porém, quando as tecnologias da informação se tornaram populares, esta fórmula se desgastou. Os fatores que ocasionaram o desgaste são explicados por decorrência da facilidade de se acessar informações e conteúdos também fora da escola, já que agora existem muitos conteúdos disseminados, que podem ser acessados a qualquer momento. A abundância de informação também pode ser um problema, visto que muitas pessoas não estão intelectualmente preparadas para gerenciar tanto conteúdo de diferentes qualidades. Segundo Valente (1999, p. 29), “A mudança pedagógica que todos almejam é a passagem de uma educação totalmente baseada na transmissão da informação, na instrução, para a criação de ambientes de aprendizagem nos quais o aluno realiza atividades e constrói o seu conhecimento"'. Entretanto, a construção do conhecimento na sociedade de informação muitas vezes não é realizada por conta da falta de inclusão das tecnologias. 
Discussões acerca da implantação da informática educacional começam a acontecer em decorrência dessa falta de falta de contextualização do mundo digital dentro da escola, que segue, muitas vezes, um modelo educacional tradicional que não consegue atender às necessidades do indivíduo inserido na sociedade da informação.

[...] a escola, que se constitui como um espaço de desenvolvimento de práticas sociais se encontra envolvida na rede e é desafiada a conviver com as transformações que as tecnologias e mídias digitais provocam na sociedade e na cultura, e que são trazidas para dentro das escolas pelos alunos, costumeiramente pouco orientados sobre a forma de se relacionar educacionalmente com esses artefatos culturais que permeiam suas práticas cotidianas [...] (ALMEIDA; SILVA, 2011, p. 5).

Infelizmente a implantação da informática educacional não é simples. A maior parte dos educadores não compreende a importância dessas ferramentas, pois fazem parte de outra geração. Segundo Prensky (2001, tradução nossa), “[...] Os professores de hoje têm que aprender a se comunicar na língua e estilo de seus estudantes [...]”, e isso implica na necessidade da aplicação dos conteúdos ensinados dentro da realidade digital.

Grande parte deles não possui experiência suficiente para utilizar computadores, videogames, entre outros. Para Prensky (2001), as novas gerações, denominadas "nativos digitais", constituem-se em indivíduos que já nasceram em um momento histórico em que o mundo digital já estava estabelecido, por isso, essas pessoas não sentiram dificuldade em se adaptar ao mundo influenciado pelas tecnologias. Já os “imigrantes digitais", são todas as pessoas que viveram sem a influência desses mecanismos. Imigrantes digitais também têm pouca intimidade com as tecnologias e habilidades ligadas à essas novas ferramentas, ao contrário dos nativos digitais, que aperfeiçoam essas habilidades naturalmente no decorrer de suas vidas (PRENSKY, 2001).

A insistente utilização de métodos educacionais desligados das mídias digitais transforma o processo de construção do conhecimento sem sentido e desinteressante. A globalização e a ascensão da internet também modificaram a forma de encontrar conhecimento pois "O mundo encontra-se conectado, as pessoas também, as informações e os conhecimentos são constantemente compartilhados de forma democrática, os saberes são facilmente acessados por todos" (FERREIRA, 2016).

Metodologias atuais e recorrentes não causam um efeito inspirador e prazeroso no estudante, e isso se aplica, consequentemente, na formação do professor, que não é mais visto como a única fonte transmissora de conhecimento, especialmente no estudo da língua inglesa 
como língua estrangeira. A língua inglesa desempenha um papel exclusivo no mundo globalizado, já que foi aderida como uma espécie de língua universal, principalmente no ambiente digital, e por conta disso, os conhecimentos acerca da língua inglesa, começaram a serem alastrados rapidamente na comunidade virtual. Ter contanto com a língua estrangeira se tornou muito mais simples e acessível.

Consequentemente, nota-se que abordagens de ensino de língua inglesa devem ser auxiliadas e integradas pelas tecnologias modernas. É neste contexto que se insere o potencial de um professor que saiba utilizar as tecnologias a seu favor, criando aulas dinâmicas e contextualizadas na sociedade atual.

\section{O ENSINO DE LÍNGUA INGLESA E OS RECURSOS TECNOLÓGICOS}

Mercado (2004) aponta que as tecnologias podem ser utilizadas para gerar situações de aprendizagem com maior qualidade, ou seja, para criar ambientes em que a problematização, a atividade reflexiva, a atitude crítica, a capacidade de decisão e a autonomia sejam privilegiadas. Esses ambientes devem ser trazidos como partes de situações reais, para que assim, ocorra uma relação daquilo que o aluno está estudando com a sua vida. A forma de ensinar língua inglesa muitas vezes desconsidera a necessidade de retratar situações reais de aprendizagem, o que é muito necessário, já que uma língua é mediadora de diversas relações sociais. De acordo com Vilaça (2010), a respeito do ensino de línguas estrangeiras, é fácil perceber a aplicação prática da matéria, já que a língua inglesa é utilizada exaustivamente em ambientes de trabalho, e é considerada uma língua global. Porém, muitas metodologias de ensino insistem em trabalhar os conteúdos utilizando estratégias que subestimam o uso prático da língua, trazendo atividades que não ligam a língua inglesa ao seu uso real.

Os alunos se sentem desmotivados e, muitas vezes, entediados com metodologias que não trazem situações reais de diálogos e outros tipos de textos na língua estrangeira. As instituições de ensino, principalmente as públicas, trabalham exaustivamente com exercícios gramaticais de memorização, trazendo sentenças desconexas e sem aplicação real. Essa tendência pedagógica, além de desestimulante, é prejudicial para o estudo da estrutura da língua já que "a construção de conhecimentos linguísticos é cumulativo. Logo, está em constante movimento e "conteúdos" de semestres ou anos anteriores não podem ser "esquecidos" ou “apagados" para dar espaço para novos saberes" (VILAÇA, 2010, p 46). 
Por conta disso, não é proveitoso estudar gramática a partir de orações desconectadas; a estrutura da língua é formada por um conjunto de vários elementos gramaticais que precisam ficar conectados para formar um texto.

A utilização das mídias digitais no ensino com pouca preparação não basta para solucionar os problemas citados acima, essas ferramentas devem agir como auxiliadoras.

[...] não basta apenas a presença de recursos tecnológicos nas salas de aula, já que, o processo ensino-aprendizagem se dá na prática relacionada com a maneira como esses recursos são utilizados, pois: a tecnologia deve servir para enriquecer o ambiente educacional, propiciando a construção. Nesse sentido, o professor é fundamental no processo de aprendizagem, no qual a principal função deste é ser um criador de ambientes de aprendizagem e de valorização do educando; a inovação não está restrita ao uso da tecnologia, mas sim na maneira de como o professor vai usar os recursos, criar projetos metodológicos que levam a produção do conhecimento, também deve haver diálogo, compreensão, respeito mútuo e a afetividade, interação e então consequentemente a tão esperada aprendizagem. [...] (KOCH, 2013, p. 15).

Fica claro que os pontos positivos da implantação dos recursos tecnológicos nas salas de aula só são atingidos através da mediação de um professor, e quando isso acontece, os benefícios são muitos. Koch (2013, p. 17) também afirma que "as tecnologias podem auxiliar como ferramenta de apoio, assim alunos se sentirão estimulados a buscar e socializar com esses recursos de forma a melhorar seu desempenho escolar através de pesquisas, jogos e atividades monitoradas."

As TIC's, como ferramentas de apoio, podem ser utilizadas de diversas maneiras, já que fica evidente que a presença da língua inglesa é primordial na esfera dessas tecnologias.

O computador pode ser uma ferramenta muito útil ao professor na transmissão de informações (ajuda estruturá-las) aos seus alunos, pois com todos os seus recursos, enriquece esse processo: dentro das salas de aula, junto com o quadro, o giz, o vídeo, a TV, o som, os mapas, os livros, os gibis, as revistas, os jogos pedagógicos, a cola, a tesoura, o lápis de cor e ainda na sala de aula junto com o professor e com os alunos, dentro da proposta pedagógica da escola. Para fazer o que? O seu uso vai depender da visão do professor sobre o que é ensinar e o que é aprender; da visão do professor de como se constrói conhecimento (DINIZ, 2001, p. 44).

Em vista disso, a aplicação desses aparatos no ensino se diversifica de acordo com as características didáticas adotadas pelo professor ou pela instituição de ensino. É possível até mesmo prosseguir o ensino de língua inglesa com uma metodologia tradicional utilizando as TIC's, com exercícios repetitivos de fixação realizados em uma tela de computador, mas também é possível desenvolver projetos de ensino e aulas diferenciadas que instiguem e 
motivem os alunos os colocando em posição de investigadores do conhecimento, construindo um caráter de autonomia.

Conduzindo as tecnologias para uma realidade mais próxima do século XXI, explora-se aparatos tecnológicos mais inovadores e populares, como os videogames, muito populares na sociedade e em grande parte dos alunos. Os videogames têm muita capacidade para enriquecer as aulas de língua inglesa. Para compreender as possibilidades da utilização dessa ferramenta, torna-se necessário entender o conceito de videogame:

"Um videogame é um jogo que jogamos graças a um aparato audiovisual e que pode ser baseado em uma história" (ESPOSITO, 2005, tradução nossa). Então, os videogames são compreendidos como tecnologias multimídias que trazem, junto a elas, jogos. Segundo Huizinga (2007), a respeito da definição do conceito de jogo:

[...] Ele se insinua como atividade temporária, que tem uma finalidade autônoma e se realiza tendo em vista uma satisfação que consiste nessa própria realização. É pelo menos assim que, em primeira instância, o ele se nos apresenta: como um intervalo em nossa vida quotidiana. [...] (HUIZINGA, 2007, p. 12)

Além de apresentar características lúdicas, um jogo precisa conter alguns atributos para ser denominado como tal.

O jogo inicia-se e, em determinado momento, "acabou". Joga-se até que se chegue a um certo fim. Enquanto está decorrendo tudo é movimento, mudança, alternância, sucessão, associação, separação. E há, diretamente ligada à sua limitação de tempo, uma outra característica interessante do jogo, a de se fixar imediatamente como fenômeno cultural. Mesmo depois de o jogo ter chegado ao fim, ele permanece como uma criação nova do espírito, um tesouro a ser conservado pela memória. É transmitido, torna-se tradição [...] (HUIZINGA, 2007, p. 12).

Cada experiência com uma partida proporciona novos conhecimentos e novas recompensas, seja pessoalmente ou dentro do próprio jogo. Os jogos também devem seguir outras características de estrutura como a existência das regras: “Todo jogo tem suas regras. São estas que determinam aquilo que "vale" dentro do mundo temporário por ele circunscrito. As regras de todos os jogos são absolutas e não permitem discussão” (HUIZINGA, 2007).

Os videogames logo adquiriram estruturas mais complexas e desafiadoras, exigindo mais reflexão e pensamento para serem superados. Os aspectos cognitivos presentes no ato de jogar um videogame acontecem de várias maneiras e podem ser considerados como um 
aprendizado. O desenvolvimento da complexidade desta multimídia fez com que novos gêneros surgissem, agradando vários tipos de públicos.

Antes dos avanços e diversificações, os videogames traziam o estigma da infantilidade, a ideia de que esta atividade poderia ser destinada apenas para crianças ou para adultos "matarem o tempo". Mas na verdade, um videogame não se limita apenas a uma atividade recreativa. O videogame é, sim, na maioria das vezes, divertido, mas é preciso assimilar as características de um jogo que envolvem desafios e recompensas. Essa estrutura motiva o jogador e pode englobar conteúdos de língua inglesa.

De acordo com Gee (2003), existem princípios de aprendizagem que os jogos incorporam. Entre eles, a interação, desafio, exploração e produção. Os jogos interagem ativamente e respondem aos atos cometidos pelo jogador, como um feedback, proporcionando um grande efeito de motivação e a vontade de resolver novos problemas e desafios. O desafio nos videogames funciona como um sistema de superação de tarefas anteriores, a cada nível avançado, o jogador se depara com novos desafios em que é preciso assimilar conhecimentos anteriores para superá-los. Os princípios de exploração e produção estão relacionados a possibilidade de que cada jogador pode traçar seu próprio caminho em cada jogatina, explorando elementos que o interessa e customizando o gameplay.

Esses princípios podem ser facilmente relacionados a outro favor, a motivação.

Há, por exemplo, dois tipos de motivação: a intrínseca e a extrínseca. A primeira se refere à motivação para trabalhar com aquilo que é considerado interessante, empolgante ou pessoalmente desafiador. O segundo tipo, por sua vez trata da motivação para se trabalhar em um determinado assunto a fim de obter uma recompensa ou vencer um concurso. (MATLIN, 2004, p. 403 apud SENA; COELHO, 2012, p. 139)

A motivação intrínseca presente nos videogames funciona com base nos desafios e momentos de exploração. Os jogadores sentem o desejo e o prazer de continuarem jogando o jogo para encontrarem novas descobertas e superarem desafios difíceis; acontece uma realização pessoal ao prosseguir no jogo.

De acordo com Gee (2003), no que diz respeito a aprendizado nos videogames, a mente humana funciona como um computador no processo de interpretação do conhecimento. Quando a mente se esforça pra resolver novos problemas, ela tenta acessar conhecimentos anteriores e já adquiridos para usá-los na resolução do novo desafio.

“Os bons videogames incorporam bons princípios de aprendizagem” (Gee, 2007, tradução nossa). O desenvolvimento cognitivo que um jogador realiza a partir da estrutura de

$$
\text { RELEDUC | ISE | v. } 3 \text { | n. } 1 \text { | dez. } 2020
$$


um videogame aflora a autonomia e o prazer em aprender, resolvendo desafios cada vez mais difíceis o que motiva na continuidade da sequência do game. Além do aspecto do prazer, aprender realizando atividades divertidas faz com que o processo de aprendizagem aconteça com muito mais naturalidade e com pouca tensão.

\section{OS JOGOS NO CONTEXTO DE APRENDIZAGEM DA LÍNGUA INGLESA}

Existe uma grande diversidade de gêneros e públicos no universo dos videogames. Por isso, é importante atentar-se apenas aos tipos de jogos que carreguem algum valor pedagógico que beneficie a aprendizagem da língua inglesa como segunda língua. $\mathrm{O}$ valor pedagógico pode ser medido através da análise dos processos, desafios e objetivos que o game proporciona. De fato, um bom jogo precisa carregar bons atributos de interação, ela funciona na forma de enfrentamento de desafios e progressão das etapas. Gee (2005, p. 6, tradução nossa) afirma que “[...] Em um videogame, jogadores fazem as coisas acontecerem. [...] Videogames são interativos. Os jogadores fazem algo e o jogo faz algo de volta para o jogador agir de novo $[\ldots] "$.

O jogador de um videogame age sobre o jogo. O leitor de um livro ou o espectador de um filme processa a informação de modo receptivo [...] $\mathrm{O}$ videogame vai mais longe: o jogador, além de olhos e ouvidos, usa as mãos e, em alguns jogos, o corpo inteiro; não apenas assiste ao que acontece, vendo a ação do lado de fora da tela, mas interfere no rumo da ação, como se estivesse do lado de dentro (LEFFA et al., 2012, p. 220).

Essa constante interação e participação ativa do jogador dentro dos mecanismos de um game propicia a busca da autonomia, encorajando reflexões críticas e distancia o aprendiz do processo de aprendizagem em que ele é tratado como receptor passivo do conhecimento. Os games criam mundos em que os jogadores sentem que suas atitudes e decisões importam para a trajetória. (GEE, 2005, p. 6-7).

Diante das contribuições de Gee (2003), a respeito do aspecto das experiências, atitudes e decisões que o game apresenta, torna-se possível fazer uma relação com as hipóteses de Krashen(1982) sobre aquisição de línguas e filtro afetivo.

Para que ocorra a aquisição, é necessária a exposição de insumos para que possa avançar para o próximo nível. O insumo abrange uma quantidade de amostras da língua alvo que fazem o aprendiz progredir e alcançar maior complexidade na língua que está aprendendo (VOLUZ, 2013, p. 31). Os insumos estão presentes nos bons videogames, aqueles que apresentam uma boa quantidade de textos, diálogos e enredo interessante. Nesses jogos, é necessário

$$
\text { RELEDUC | ISE | v. } 32 \text { | n. } 1 \text { | dez. } 2020
$$


compreender e relacionar esses insumos para progredir. A necessidade de contextualizar e interligar as informações para avançar no desafio; essas informações podem aparecer como elementos, como por exemplo objetos e personagens, mas também existe uma grande necessidade de interpretar linguagens.

O filtro afetivo é outra hipótese de Krashen (1982) e caracteriza-se como um bloqueio dos insumos. Esse bloqueio mental acontece por meio de fatores que inibem o aluno que está em processo de aquisição, não permitindo que os conteúdos dos insumos cheguem até ele (VOLUZ, 2013, p. 32-33).

Krashen estabelece três variáveis afetivas fundamentais: atitude, motivação e personalidade. A atitude pode ser considerada mais significativa que a aptidão, já que a atitude negativa do aprendiz aumenta o filtro e bloqueia os insumos, mesmo com perfeitas possibilidades de compreensão do que está sendo ensinado (VOLUZ, 2013, p. 33). Experiências com bons gêneros de videogames, aqueles bons para a aprendizagem, carregam maior motivação e reduz uma atitude negativa.

Gee (2003) traz a listagem de 36 princípios que distribuem o que os videogames têm a ensinar sobre aprendizagem e alfabetização. O sexto princípio (princípio da moratória psicossocial) diz que, em um game, “Aprendizes podem correr riscos em um espaço em que as consequências do mundo real são reduzidas" (GEE, 2003, p. 207, tradução nossa).

Um jogo traz possibilidades de tentativa e erro, e consequências ruins quando se erra não são sentidas na realidade da pessoa, por isso, existe uma grande liberdade para vivenciar novas experiências e superar desafios, aprendendo com os erros e não tendo receio de tentar novamente, caso erre. $\mathrm{Na}$ verdade, um videogame é feito de possibilidades e existem várias formas de resolver os problemas (GEE, 2005).

Gee (2003, p. 209) também aponta, em um dos seus 36 princípios, o princípio de rotas múltiplas. O princípio alega a liberdade que um jogador tem dentro de um game a respeito das diferentes maneiras possíveis de conseguir o progresso, não tendo a necessidade de ficar preso em etapas monótonas e maçantes. Nos videogames, muitas vezes, o jogador pode tomar decisões e construir sua performance a partir delas.

$\mathrm{Na}$ verdade, erros são bastante frequentes enquanto se joga um videogame. Mas, diferentemente de uma situação real como uma sala de aula, em que um equívoco causaria constrangimento ou desconforto, durante uma jogatina não existem riscos reais para o jogador. Essa característica remete novamente aos princípios de Gee (2003); o sexto princípio, nomeado como moratória psicossocial. Mesmo com a existência do risco do erro, o jogador não as teme, 
as consequências no mundo real são quase ou totalmente nulas, esses padrões caracterizam o princípio. Esse ambiente tranquilo favorece o aprendizado de uma língua estrangeira, como o inglês, pois o aprendiz não se sentirá tão prejudicado caso cometa algum erro durante o estudo, mesmo que de forma indireta, de um conteúdo da língua.

Durante a interação no videogame, é importante compreender símbolos linguísticos e assimilá-los, como diálogos e arquivos de texto. A partir da assimilação dos conteúdos, entendese os mecanismos das fases e atinge-se o progresso, fazendo corretamente o que aquela etapa propõe. Além disso, o erro é recorrente e o jogador pode tentar novamente para conseguir um progresso melhor, reforçando as duas características que todo videogame têm: a tentativa e o erro.

Os símbolos linguísticos fazem parte do mundo real, como muitas outras coisas reais que são recriadas dentro de um ambiente virtual no videogame. Basicamente, um game cria um mundo virtual alternativo que simula desafios a serem resolvidos por jogadores. Um dos grandes atrativos de um videogame é sua ambientação, é possível recriar mundos deslumbrantes e personagens cativantes, fazendo com que quem esteja jogando se sinta interessada em resolver os problemas.

Os jogos são feitos a partir de um fluxo de imagens visuais. Então eles compartilham a sintaxe e a semântica do mundo visual humano. Mas, como os cientistas, os jogares têm ferramentas especiais que permitem ver o mundo dos jogadores de maneira diferente. Os jogadores têm controladores e avatares através dos quais podem manipular o mundo do jogo para atingir objetivos e resolver problemas. [...] (GEE, 2007, 2014 apud GEE, 2015, p. 20, tradução nossa)

Os jogos têm a função de recriar mundos em um ambiente virtual, mundos que são construídos a partir de signos já familiares da cultura do homem. “[...] o signo não ocupa o lugar do objeto fisicamente, mas ocupa sim seu lugar de um ponto de vista lógico que uma mente interpretadora pode compreender, sem que necessariamente o objeto esteja presente" (LIMA, 2008, p. 54). A compreensão de um signo existente sem que ele esteja de fato fisicamente representado traz um enriquecimento e prazer para o jogador, por conta da grande imersão. Ao mesmo tempo em que existe uma imersão no mundo e nos desafios, acontece uma imersão na língua, já que alguns gêneros trazem caixas de diálogos e descrições de cenários e objetos a todo momento, e em inglês.

O princípio de aprendizagem número 20 (Princípio multimodal), menciona que o conhecimento e os significados nos games são apresentados de diferentes formas, como sons, 
imagens, textos e símbolos (GEE, 2003). Essas formas precisam ser assimiladas em conjunto, para que assim, acontece o avanço naquele desafio. Por conta disso, torna-se necessária a análise de símbolos linguísticos, mesmo que de forma indireta. Gee (2003, p. 109, tradução nossa) também afirma que "Nos videogames, os jogadores logo aprendem a "ler" os ambientes físicos e eles estão em busca de pistas sobre como proceder através deles. [...].",

O princípio do texto (GEE, 2003) afirma que os signos linguísticos são compreendidos de acordo com experiências incorporadas previamente e que são retomadas, não tendo um significado puramente verbal no game. O significado puramente verbal ocorre quando o jogador possui uma quantidade importante de experiências incorporadas (GEE, 2003). O jogador se vê na necessidade de unir as informações já presentes na sua vivência atual do game e criar métodos para enfrentar a próxima etapa, a cada desafio as informações aparecem de forma mais complexa, exigindo mais lógica.

A necessidade de "ler" o ambiente torna os bons videogames ótimas ferramentas de aprendizado, exigindo raciocínio lógico e leitura. “[...] O valor educativo de um videogame é uma variável opcional, já que este valor pode ou não estar presente no jogo, ao contrário do valor de entretenimento, que é uma variável de presença obrigatória [...]” (LEFFA et al., 2012, p. 219).

Em sua teoria dos princípios de aprendizagem e alfabetização com a utilização dos games, Gee (2003, p. 209) afirma que, nos games, “Os significados dos signos (palavras, ações, objetos, artefatos, símbolos, textos, etc.) estão situados na experiência incorporada. Os significados não são gerais ou descontextualizados [...]”.

Portanto, gêneros de games proveitosos no âmbito do ensino de línguas expressam para o jogador que símbolos apresentados não fazem parte de um processo imediatista. Na verdade, os conteúdos aprendidos fazem parte de um sistema abrangente que deve ser formado continuamente para superar desafios ainda maiores. (GEE, 2014) A análise dessa característica do videogame relaciona-se ao próprio mecanismo da língua, em que todos os conteúdos envolvidos associam-se e formam um grande sistema, complexo e contextualizado.

\section{CONSIDERAÇÕES FINAIS}

É possível afirmar que o ensino da língua inglesa como língua estrangeira deve se adequar ao novo ritmo da sociedade, propiciando metodologias que desenvolvam a autonomia de seus alunos a partir da utilização de tecnologias da informação, ferramentas intimamente 
ligadas à disposição das relações sociais do século XXI. Entretanto, é importante frisar que essas tecnologias devem realizar um papel auxiliador no processo de construção do conhecimento, e o professor deve aparecer como agente mediador. A inserção dos jogos digitais no ensino de língua inglesa, mídia digital alvo de estudo desta pesquisa, conduz um aprendizado divertido e motivador, em que as estruturas linguísticas da língua aparecem como inputs internalizados nos desafios dos jogos. Ambientação magnífica, enredo interessante e outros fatores causam um efeito motivador e gerador de diversão, enquanto a presença de mecanismos linguísticos como diálogos, anotações e ordens exigem que o jogador compreenda de forma direta e indireta como esses mecanismos funcionam e como se relacionam, para que assim, seja possível superar os desafios propostos.

\section{REFERÊNCIAS}

ALMEIDA, M. E. B; SILVA, M. G. M. Currículo, tecnologia e cultura digital: espaços e tempos de web-currículo. Revista e-curriculum, São Paulo, v. 7, n. 1, abr. 2011. Disponível em: http://revistas.pucsp.br/index.php/curriculum. Acesso em: 11 maio 2019.

BLANCO, E; SILVA, B. Tecnologia educativa em Portugal: conceito, origens, evolução, áreas de intervenção e investigação. Revista portuguesa de educação, Braga, v. 6, n. 3, p. 37-55, 1993.

CRUZ, J. A. S; BIZELLI, J. L. Sociedade, tecnologias e educação: as tecnologias da informação e comunicação e o pensar da sociedade concreta. Cad. Ed. Tec. Sociedade, Inhumas, v. 5, p. 258-266, 2014. Disponível em:

http://www.cadernosets.inhumas.ifg.edu.br/index.php/cadernosets/article/newFile/191/96. Acesso em: 11 maio 2019.

DINIZ, S. N. F. O uso das novas tecnologias em sala de aula. 2001. 173 f. Dissertação (Pósgraduação em engenharia da produção)-Universidade Federal de Santa Catarina, Florianópolis, 2001.

DURKHEIM, E. Educação e sociologia. 10. ed. Tradução De Lourenço Filho. São Paulo. Melhoramentos, 1975.

ESPOSITO, N. A short and simple definition of what a game is. In: DiGRA, digital games research association, 5., 2005, Vancouver. Anais [...]. Vancouver: DiGRA, 2005.

FERREIRA, J. K. S. A formação do professor de língua inglesa para o uso das tecnologias da informação e comunicação em sala de aula. In: CONEDU, congresso nacional de educação, 3., 2016, Natal. Anais [...]. Natal: CONEDU, 2016. 
GEE, J. P. Discourse analysis of games. Disponível em: http://jamespaulgee.com/pdfs/Discourse\%20Analysis\%20of\%20Games.pdf. Acesso em: 7 jun. 2019

GEE, J. P. Good videogames and good learning. Disponível em: http://www.academiccolab.org/?s=gee\#art. Acesso em: 7 jun. 2019.

GEE, J. P. Learning by desing: good video games as learning machines. E-Learning, v. 2, n. 1, 2005. Disponível em: https://journals.sagepub.com/doi/pdf/10.2304/elea.2005.2.1.5. Acesso em: 10 set. 2019.

GEE, J. P. Reading, language development, video games, and learning in the 21 century. Disponível em: http://www. http://jamespaulgee.com/pdfs/Reading,\%20Language\%20Development,\%20and\%20Games.p df. Acesso em: 10 set. 2019.

GEE, J. P. Video games, desing, and aesthetic experience. Rivista di estética, v. 3, n. 63, 2016. Disponível em: https:// https://journals.openedition.org/estetica/1312. Acesso em: 10 set. 2019.

GEE, J. P. What videogames have to teach us about learning and literacy. New York: Palgrave/Macmillan, 2003.

GOUVEIA, L. M. B. Sociedade da informação: notas de contribuição para uma definição operacional. Revista da Faculdade de Ciências Humanas e Sociais, Porto, n. 1, nov., 2004. Disponível em: http://www.homepage.ufp.pt/Imbg/reserva/Ibg-socinformacao04.pdf. Acesso em: 11 maio. 2019.

HUIZINGA, J. Homo ludens: o jogo como elemento da cultura. Tradução João Paulo Monteiro. 5. ed. São Paulo: Perspectiva, 2007.

$\mathrm{KOCH}, \mathrm{M}$. Z. As tecnologias no cotidiano escolar: uma ferramenta facilitadora no processo ensino-aprendizagem. 2013. 35 f. Dissertação (pós-graduação a distância especialização lato sensu em gestão educacional)-Universidade Federal de Santa Maria, Sarandi, 2013.

KRASHEN, S. D. Principles and practice in second language acquisition. New York: Pergamon Institute of English, 1982.

LEFFA, V. J. et al. Quando jogar é aprender: o videogame na sala de aula. Rev. Estudos Linguísticos, Belo Horizonte, v. 20, n. 1, p. 209-230, jan./jun. 2012.

LIMA, C. W. F. A construção da imagem realista em jogos de videogame. Um estudo sobre as representações imagéticas nos games de nova geração. 2008. 145 f. Dissertação (Mestrado em Comunicação e Semiótica) - Pontifícia Universidade Católica de São Paulo, São Paulo, 2008.

MERCADO, L. P. L. (Org). Tendências da utilização das tecnologias da informação e comunicação na educação. Maceió: edUFAL, 2004. 
PREMSKY, M. Digital native, digital immigrants. Digital native immigrants. On the horizon, MCB university press, Bingley, v. 9, n. 5., 2001. Disponível em: https://www.marcprensky.com/writing/Prensky\%20$\% 20$ Digital\%20Natives, \%20Digital\%20Immigrants\%20-\%20Part1.pdf. Acesso em: 11 maio. 2019.

SENA, A; COELHO, D. K. Motivação dos jogadores de videogames-uma breve visão sobre as técnicas de engajamento. In: SBGames, simplório brasileiro de jogos e entretenimento digital, 11., 2012, Brasília. Anais [...]. Brasília: SBGames, 2012.

VALENTE, J. A. (Org). O computador na sociedade do conhecimento. Campinas: Nied, Unicamp, 1999. p. 29-48.

VILAÇA, M. L. C. Aprendizagem de língua inglesa: das dificuldades à autonomia. Revista acadêmica do instituto de humanidades, Duque de Caxias, n. 33, 2010. Disponível em: http://publicacoes.unigranrio.edu.br/index.php/reihm/article/view/1220. Acesso em: 7 jun. 2019.

VOLUZ, T. C. As hipóteses de Krashen: influências e possíveis aplicações no ensino de espanhol como língua estrangeira. Versalete, Curitiba, n. 1, jul.-dez. 2013. Disponível em: http://www.revistaversalete.ufpr.br. Acesso em: 10 set. 2019. 